\title{
MODEL PEMBELAJARAN PENDIDIKAN AGAMA ISLAM DALAM MEMBENTUK SIKAP MULTIKULTURALISME
}

\author{
M. Jamhuri*, Maskuri** \\ *Universitas Yudharta Pasuruan \\ Email : jamhurim2017@gmail.com \\ **Universitas Islam Malang \\ Email : maskuri@unisma.ac.id
}

\begin{abstract}
Abstrak
Nilai-nilai multikulturalisme dalam pembelajaran pendidikan agama Islam di Universitas Yudharta Pasuruan telah dilaksanakan dengan baik, terbukti telah terjadi sikap saling menghormati, toleransi, sikap saling menghargai, tolong menolong dan lain sebagainya, baik antar mahasiswa atau antar dosen dan atau antar mahasiswa dan dosen Universitas Yudharta Pasuruan dan dengan masyarakat. Pelaksanaan pembelajaran pendidikan agama Islam Universitas Yudharta Pasuruan telah terintegrasi oleh prinsip-prinsip aswaja dan nilai-nilai multikultural, baik pada kegiatan pelaksanaan pembelajaran, ektra kurikuler atau pada kegiatan keagamaan mahasiswa Universitas Yudharta Pasuruan.
\end{abstract}

Kata kunci: prinsip-prinsip aswaja, multikultural, model pembelajaran

\section{Abstract}

The values of multiculturalism in learning Islamic education at the University of Yudharta Pasuruan have been well implemented, it has been proven that there has been an attitude of mutual respect, tolerance, mutual respect, help and so on, both between students or between lecturers and or between students and University lecturers Yudharta Pasuruan and with the community. The implementation of the learning of Islamic religious education at Yudharta Pasuruan University has been integrated by the principles of Aswaja and multicultural values, both in the implementation of learning activities, extra curricular or in religious activities of students of Yudharta Pasuruan University.

Keywords: aswaja principles, multicultural, learning models

\section{PENDAHULUAN}

Sikap multikultural adalah sebuah cita-cita mulia dari KH. Sholeh Bahrudin, pembina Yayasan Darut Taqwa beliau mendirikan Perguruan Tinggi Naungan Pondok Pesantren, yang ingin mencetak manusia yang sosialis, Pancasilais, religius dan multikulturalisme, yang seimbang dalam menjalani urusan dunia dan urusan akhirat, memiliki kemampuan untuk bergaul membawur sesama bangsa tanpa membedakan agama, suku, ras, 
kebudayaan dan ataupun warna kulit. Karena Indonesia di merdekakan oleh masyarakat yang majemuk, sesuai dengan bhinneka tunggal ika.

KH. Sholeh Bahruddin mengatakan, bahwa menanggapi berbagai gejolak yang ada di masyarakat Indonesia, Kalau masyarakat terus menerus bentrok seperti ini akan jadi apa nantinyaIndonesia ini. Sebab kalau hanya bentrok antar politik Partai korban yang meninggal dunia tidak seberapa banyak, akan tetapi jika bentrok antar agama, etnis atau suku, bisa menelan berjuta-juta jiwa.

Melihat femomena di atas, peneliti tertarik ingin mengetahui fakta di lapangan tentang model pembelajaran pendidikan agama Islam dalam membentuk sikap multikultural (kajian tentang prinsip-prinsip aswaja dan dasar-dasar multikultural dalam proses pembelajaran di Universitas Yudharta Pasuruan).

\section{METODE}

Peneliti menggunakan penelitian kualitatif sebab peneliti ingin mengetahui fenomena serta perkembangan yang ada sebagai kesatuan yang diketahui secara utuh tanpa terikat oleh suatu variabel atau hepotesis tertentu. Karena pendekatan ini merupakan proses penelitian yang menghasilkan data deskriptif berupa kata-kata, tertulis, dan perilaku yang dapat diamati dalam melakukan penelitian

Desain yang digunakan peneliti adalah fenomenologi Desain penelitian,yang rencana dan struktur penelitian dibuat sedemikian rupa, sehingga dapat diperoleh jawaban atas pertanyaan-pertanyaan dalam penelitian, dari masing-masing individu memberikan jawaban dari setiap kasus atau pengalaman yang mereka ketahui terkait dengan pertanyaan tersebut diatas.

Pada penelitian ini yang menjadi lokasi penelitian adalah Universitas Yudharta Pasuruan yang berada di Pondok Pesantren Ngalah, Jl.Yudharta No.7 (Pesantren Ngalah) Sengonagung Purwosari Pasuruan.

Pengumpulan data adalah sesuatu yang sangat penting dalam penelitian ilmiah. Pengumpulan data merupakan prosedur yang sistematis dan standar untuk memperoleh data yang diperlukan.

Kegiatan pokok atau utama dalam penelitian ini adalah pengumpulan data. Pengumpulan data dalam penelitian kualitatif bersifat induktif konseptual, emik pos-priori dan holistic kontekstual, Islitilah induktif konseptual menunjukkan pada salah satu karakteristik yang lebih mementingkan aspek penyusunan konsep, proposisi atau teori.

Metode yang peneliti gunakan dalam mengumpulkan data adalah: wawancara, observasi, dan domentasi. Analisis data merupakan salah satu tahapan yang saya kerjakan setelah memperoleh informasi melalui beberapa 
teknik pengumpulan data, dan bertujuan untuk menyempitkan dan membatasi temuan-temuan sehingga menjadi suatu data yang teratur dan akurat di Universitas Yudharta Pasuruan.

Setelah semua data yang telah peneliti peroleh dari hasil dari penelitian di Universitas Yudharta Pasuruan. Sebelum peneliti menarik kesimpulan pertama kali yang peneliti lakukan adalah memverivikasi serta mengecek serta menggali atau mengkaji ulang dari hasil penelitian baik dari hasil wawancara dengan beberapa informan, observasi dan dokumentasi di Universitas Yudharta Pasuruan, yang tiada lain bertujuan untuk memahami pola-pola, penjelasan, sebab dan akibat atau proposisi. Disamping itu peneliti lakukan reduksi data, penyajian data dari semua data hasil penelitian atau verifikasi data dari kegiatan-kegiatan sebelumnya

\section{PEMBAHASAN}

Pendidikan ialah usaha manusia untuk menjadi manusia. Ada dua kata yang penting dalam kalimat itu, pertama "membantu" dan kedua "manusia". Manusia perlu dibantu agar menjadi manusia. Seseorang dapat dikatakan telah menjadi manusia bila telah memiliki nilai (sifat) kemanusiaan. Hal ini menunjukkan bahwa tidaklah mudah menjadi manusia. Karena itulah sejak dahulu manusia sering gagal menjadikan dirinya sebagai manusia. Jadi, tujuan mendidik ialah memanusiakan manusia. Agar tujuan itu dapat dicapai dan agar progam dapat disusun maka cici-ciri manusia yang telah menjadi manusia itu haruslah jelas. ${ }^{1}$ Manusia dididik atau dimasukkan dalam dunia pendidikan supaya menjadi manusia yang baik. Kata Ahmad Syafii Maarif, ${ }^{2}$ manusia yang baik merupakan sosok manusia yang tidak menghabiskan masa hidup yang ringkas ini dengan sia-sia.

Driyakarya menyatakan, bahwa dalam suatu kehidupan terdapat sekian banyak nilai, wert, atau values, namun kalau harus diklasifikasikan, hanya ada dua nilai saja, yaitu nilai alat (tool) dan nilai tujuan. ${ }^{3}$ Pendidikan adalah proses perubahan pola pikir, pola sikap, dan pola tindak kearah yang dikehendaki. Konsep pendidikan di perguruan tinggi internasional cenderung bersifat manusiawi, realistik, egaliter, demokratis, dan religius. Pendekatan pendidikan, seperti yang dicetuskan dalam deklarasi UNESCO (1998) bahwa pendidikan diwujudkan dalam pilar learning to know; 2006), 33 .

${ }^{1}$ Ahmad Tafsir, Filsafat Pendidikan Islam, (Bandung: Remaja Rosdakarya,

${ }^{2}$ Ahmad Syafii Maarif, Membumikan Islam, (Yogyakarta: Pustaka Pelajar,1995), 11.

${ }^{3}$ Musthafa Kamal Pasha, Pendidikan Kewarganegaraan (Civic Education), (Jakarta: Citra Karsa Mandiri, 2003), 3. 
learning to do; learning to be; learning to life together. Hal ini sesuai dengan tujuan pendidikan nasional, yaitu mewujudkan pribadi anggota masyarakat madani yang bercirikan demokrasi, kepastian hukum, egaliter, penghargaan tinggi terhadap human dignity, kemajuan budaya dan bangsa dalam suatu kesatuan, dan religius. ${ }^{4}$

Kalau berpijak pada pemahaman itu, maka idealitasnya siapapun yang terdidik dengan benar, apalagi dengan pola-pola pendidikan Islam, maka tidak akan menjadi manusia-manusia yang menempuh jalan sesat atau jalan merugikan kepentingan sesama manusia. Pendidikan, apalagi menggunakan ruh dalam agama Islam, jika diselenggarakan dan berhasil ditransormasikan dalam kehidupan manusia, maka idealitasnya tidak perlu ada kekerasan atau radikalisme yang dijadikan sebagai pilihan untuk meyakinkan kepada orang lain.

Pendidikan Islam adalah pendidikan yang bertujuan untuk membentuk pribadi muslim seutuhnya, mengembangkan seluruh potensi manusia baik yang berbentuk jasmaniah maupun rohaniah, menumbuh suburkan hubungan harmonis setiap pribadi dengan Allah, manusia dan alam semesta. Dengan demikian, pendidikan Islam itu berupaya untuk mengembangkan individu sepenuhnya, maka sudah sewajarnyalah untuk dapat memahami hakikat pendidikan Islam itu bertolak dari pemahaman terhadap konsep manusia menurut Islam. ${ }^{5}$

Al-Qur'an meletakkan kedudukan manusia sebagai Khalifah Allah di bumi (Al-Baqarah: 30). Esensi makna Khalifah adalah orang yang diberi amanah oleh Allah untuk memimpin alam. Dalam hal ini manusia bertugas untuk memelihara dan memanfaatkan alam guna mendatangkan kemaslahatan bagi manusia Agar manusia dapat melaksanakan fungsinya sebagai khalifah secara maksimal, maka sudah semestinyalah manusia itu memiliki potensi yang menopangnya untuk terwujudnya jabatan khalifah tersebut. Potensi tersebut meliputi potensi jasmani dan rohani. ${ }^{6}$

Menurut Susari pendidikan Islam dalam persepektif pendidikan Islam pada umumnya mengacu pada tiga term dalam bahasa arab yaitu: alTarbiyah, al-Ta'lim dan al-Ta'dib, ketiga trem tersebut meskipun mempunyai maksud yang sama untuk mendefinisikan tentang pendidikan

${ }^{4}$ Minto Rahayu, Pendidikan Kewarganegaraan (Perjuangan Menghidupi Jati Diri Bangsa), (Jakarta: PT. Gramedia Widiasarana Indonesia, 2007), 16.

${ }^{5}$ Endang Komara, Peran Pendidikan Islam dalam Era Globalisasi, http://www.geocities.ws/endang.komara/peran_pendidikan_islam_dalam_era_globalisasi.h tm,akses 2 September 2017.

${ }^{6}$ Ibid. 
dalam Islam, namaun ketiganya mempunyai perbedaan, baik tekstual maupun kontekstual. ${ }^{7}$

Agama Islam adalah agama yang universal, yang mengajarkan kepada ummat manusia mengenai berbagai aspek kehidupan, baik duniawi maupun ukhrowi.

Dalam Surat Ali Imron ayat 164 Allah berfirman: "sungguh Allah telah memberi karunia kepada orang-orang yang beriman ketika Allah mengutus diantara mereka seorang rasul dari golongan mereka sendiri, yang membacakan kepada mereka ayat-ayat Allah, membersihkan (jiwa) mereka, dan mengajarkan kepada mereka al kitab dan al hikmah. dan Sesungguhnya sebelum (kedatangan Nabi) itu, mereka adalah benar-benar dalam kesesatan yang nyata."

Muhammad Tholchah Hasan mengatakan, bahwa Islam sebagai agama samawi, meletakkan dasar-dasar teologi dan ajaran-ajaran yang telah diuji cobakan oleh pembawanya sendiri, Nabi Muhammad saw dan berhasil meletakkan pengalaman sosial yang menjunjung tinggi prinsip-prinsip kemanusiaan dengan hak-hak asasinya, di tengah-tengah kehidupan masyarakat majemuk.

Dalam al-Qur'an nilai-nilai multikultural banyak sekali disebutkan, karena pada dasarnya bersikap akan nilai-nilai multikultural memang dianjurkan oleh Alloh pada umat manusia dalam al-Qur'an, Nilai-nilai tersebut antara Lain:

\section{a) Nilai Inklusif dan Humanisme}

Menurut Muhammad Tholchah Hasan mengutarakan tentang pentingnya nilai inklusif, kasih sayang, toleransi dan menghargai perbedaan adalah: bahwa berbagai konflik sosial yang telah menimbulkan keterpurukan di negeri ini disebabkan oleh kurangnya kemauan untuk menerima dan menghargai perbedaan, ide dan pendapat orang lain,karya dan jerih payah orang lain, melindungi yang lemah dan tidak berdaya, menyayangi sesama, kurangnya kesetiakawanan sosial, dan tumbuhnya sikap egois serta kurang kepekaan sosial. ${ }^{8}$

Human sebagai bentuk ajektif berarti bersifat manusiawi. Humanistik berarti bersifat kemanusiaan. Sedangkan humanisme berarti aliran yang bertujuan menghidupkan rasa kemanusiaan dan mencita-citakan pergaulan hidup yang lebih baik. Dari arti katanya jelas tampak bahwa humanisme merupakan faham yang menganggap manusia sebagai objek studi terpenting, terutama, pada sifat-sifat kemanusiaannya. Ketika manusia dipandang dengan segala sifat-sifat kemanusiannya, maka potensi yang ada

${ }^{7}$ Mochtar Zaman, Konstruksi Pendidikan Islam, (Jakarta: Kalam-Media, 2012), 2.

8 Muhammad Tholchah Hasan, Pendidikan Multikulturalisme sebagai Opsi Penanggulangan Radikalisme, (Malang: Universitas Islam Malang, 2016), 19. 
pada diri manusia, yakni potensi yang bersifat psikologis, sosial, dan kultural, haruslah menjadi objek perhatian secara komprehensif.

\section{b) Nilai Toleransi}

Nilai ini memandang bahwa seharusnya setiap individu atau kelompok memiliki sikap saling menghargai. Mahasiswa Universitas Yudharta Pasuruan berasal dari berbagai etnis, budaya, bahasa, agama, namun perbedaan-perbedaan tersebut tidak menjadi penghalang dalam menjalankan pergaulan sehari-hari berlangsung akrab saling memahami dan menghargai, mampu berintraksi sosial sesuai dengan norma-norma yang ada ditengah-tengah masyarakat, mampu menjunjung tinggi adat kebiasaan dan budaya.

\section{c) Nilai Musyawaroh}

H.A.R Tilaar menyatakan, bahwa seorang yang saleh melaksanakan tuntunan ajaran agama dan kepercayaannya tidak hanya didalam kehidupan kelompoknya sendiri. Kesalehan tersebut diuji oleh sikap toleransi didalam pergaulan dan komunikasi dengan sesama yang berbeda dengan dirinya. Dengan sendirinya seorang yang berakhlak mulia bertentangan dengan segala macam fanatisme, egoisme. Fanatisme tidak memberikan tempat atau ruang untuk berdialog. ${ }^{9}$

M. Nadjid Muchtar mengatakan, bahwa sikap masyarakat NU di Indonesia adalah: ${ }^{10}$

a. Sikap Tawassuth dan I'tidal:

1) Sikap tengah berintikan keadilan ditengah kehidupan bersama.

2) Menjadi kelompok panutan, bertindak lurus, bersifat membangun tidak ekstrem.

b. Sikap Tasamukh:

1) Toleran didalam perbedaan pendapat keagamaan.

2) Toleran didalam urusan kemasyarakatan dan kebudayaan.

c. Sikap Tawazun :

1) Keseimbangan dalam berkhidmat kepada Alloh SWT, berkhidmat kepada sesama manusia dan kepada lingkungan hidup.

2) Keselarasan antara masa lalu, masa kini dan masa depan.

d. Amar Ma'ruf dan Nahi Munkar.

1) Kepekaan untuk mendorong perbuatan baik.

2) Mencegah hal yang dapat merendahkan nilai-nilai kehidupan. (Muchtar, 2015;176)

9 H.A.R Tilaar. Perubahan Sosial Dan Pendidikan, pengantar pedagogik transformatif untuk indonesia, (Jakarta: PT. Rineka Cipta. 2004), 201.

${ }^{10}$ M. Nadjid Muchtar, Islam Ahlusunnah Waljama'ah Sejarah pemikiran dan dinamika NU di Indonesia, (Jakarta: 2015), 176. 
Pelaksanaan Proses Pembelajaran Pendidikan Aswaja dan dasardasar multikultural sebagai berikut: Mahasiswa melaksanakan tugas yang berkaitan dengan kedua mata kuliah pendidikan Aswaja dan mata kuliah pendidikan dasar-dasar multikultural baik tugas penelitian dimasyarakan atau tugas Presentasi.

Pelaksanaan kegiatan keagamaan di Universitas Yudharta Pasuruan yaitu: Baca Tulis Qur'an (BTQ), terutama bagi mahasiswa PAI yang statusnya sebagai guru BTQ karena mata pelajaran BTQ di Kabupaten Pasuruan diharuskan untuk di masukkan pada pelajaran sekolah dari berbagai tingkatan,

Dosen atau mahasiswa non-muslim mereka bebas tidak mengenakan pakaian sesuai dengan ajaran agamanya. Bu Estalita Kelly, Dekan Fakultas Psikologi. beliau adalah lompatan besar KH Sholeh Bahrudin yang berani memasukkan Non-muslim dalam jabatan Struktural. Seperti halnya dawuh Romo Kyai Sholeh Yudharta adalah kampus terbuka, meski berada di tengah pesantren.

Model pelaksanaan pembelajaran pendidikan agama Islam dalam membentuk sikap multikulturalisme di Universitas Yudharta Pasuruan sebagai berikut:

a) Mengintegrasikan nilai-nilai multikulturalisme ke dalam pendidikan aswaja, dan pendidikan dasar-dasar multikultural. Dalam hal ini, nilainilai multikulturalisme tidak berdiri sendiri dalam satu sub topik pada kurikulum pendidikan agama Islam, tetapi diintegrasikan kedalam sub tema bahasan yang sesuai dengan nilai-nilai multikulturalisme

b) Mengintegrasikan nilai-nilai multikulturalisme ke dalam standar kompetensi materi mata kuliah aswaja dan dasar-dasar multikultural..

Adapun inti temuan hasil penelitian berdasarkan pada fokus penelitian diatas, yaitu nilai-nilai, pelaksanaan, keunikan serta model pembelajaran pendidikan agama Islam di Universitas Yudharta Pasuruan. Adapun nilai-nilai pembelajaran pendidikan agama Islam di Universitas Yudharta Pasuruan:

1) Terbentuknya sikap toleransi, saling menghormati dan saling menghargai perbedaan baik dari kalangan sivitas akademika, dosen dan mahasiswaserta masyarakat.

2) Mereka dalam bersikap selalu berpegang teguh terhadap nilai-nilai multikultural. Seperti inklusif, toleransi, tolong menolong, kasih sayang, cinta damai dan lain sebagainya.

Aspek pelaksanaan pembelajaran pendidikan aswaja dan pendidikan dasar-dasar multikultural di Universitas Yudharta Pasuruan: 
1) Pelaksanaan pembelajaran pendidikan aswaja dan pendidikan dasar-dasar multikultural dilaksanakan di dalam kelas dan ekstra kulikuler atau tugas penelitian.

2) Dosen pengampu mengadakan evaluasi pada mahasiswa tentang keberhasilan dari pembelajaran kedua mata kuliah tersebut dan membuat laporan perkembangan mahasiswa. Berupaya meningkatkan mahasiswa agar bisa mengembangkan serta memperaktekkannya dimasyarakat.

Dalam hal keunikan pembelajaran pendidikan agama Islam di Universitas Yudharta Pasuruan:

1) Berkaitan dengan kerukunan beragama, dosen serta mahasiswa Universitas Yudharta Pasuruan, sering melakukan kunjungan ke berbagai gereja, wihara dan tempat-tempat ibadah yang lain, hal ini sebagai komitmen bahwa Universitas Yudharta Pasuruan ingin membangun kerukunan antar umat beragama supaya tidak terjadi permusuhan dan perpecahan dikalangan bangsa.

2) Pada hari minggu 21 Oktober 2018 Universitas Yudharta Pasuruan mengadakan wisuda sarjana S1, walaupun berada dibawah naungan Pondok pesantren Daruttaqwa akan tetapi Romo Kyai Sholeh disamping mengundang Menteri Ristek Mohammad.Nasir dan para Ulama' juga mengundang beberapa biarawan dan biarawati agama Katolik dari berbagai daerah seluruh Indonesia, antara lain dari Sumatra, Sulawesi, Nusa Tenggara Timur(NTT), Papua dan Timor Leste, yang mana tujuan Romo Kyai Sholeh agar mereka mendoakan para wisudawan dan wisudawati bersama Para Ulama' agar para wisudawan menjadi generasi yang berguna bagi agama, nusa dan bangsa, bernuansa multikultural dan cinta damai.

Model pembelajaran pendidikan agama Islam di Universitas Yudharta Pasuruan adalah mengintegrasikan nilai-nilai multikulturalisme dalam proses pembelajaran ke dalam standar kompetensi materi mata kuliah dasar-dasar multikultural.Cara ini dimaksudkan agar setiap dosen dapat mengembangkan nilai-nilai multikulturalisme kedalam rencana pembelajaran semester (RPS) sesuai dengan mata kuliah yang diampu, setiap dosen akan mendalami terlebih dahulu materi yang terkait dengan nilai-nilai multikulturalisme.

\section{PENUTUP}

Pertama, nilai-nilai multikultural sudah diterapkan oleh kalangan dosen, karyawan dan mahasiswa. Penerapan nilai-nilai tersebut mendapat sambutan yang baik sehingga dapat mengatasi berbagai kekurangan dalam bersikap, kedua, pelaksanaan pembelajaran pendidikan aswaja dan pendidikan dasar-dasar multikultural di Universitas Yudharta Pasuruan 
sangat menyentuh sikap para mahasiswa, mengingat materinya memuat berbagai macam dasar dan nilai tentang multikultural menurut Islam dan mengurai tentang sejarah tumbuh kembangnya Islam dari ulama nahdliyyin, ketiga, keunikan yang terjadi, antara Lain: Universitas Yudharta walau di bawah naungan Pondok Pesantren, tetapi mahasiswa sering melakukan penelitian dan kunjungan-kunjungan ke berbagai gereja, dan tempat-tempat ibadah yang lainnya, hal ini tidak lain adalah sebagai bentuk komitmen bahwa Universitas Yudharta ingin membangun kerukunan, dan keempat, model pembelajaran dari para dosen pengampu pendidikan aswaja dan pendidikan dasar-dasar multikultural: Membuat Rencana Pembelajaran Semester (RPS) dan Rencana Pelaksanaan Pembelajaran (RPP) dosen pengampu selalu memasukkan nilai-nilai Multikultural, sehingga lebih cepat merubah sikap para mahasiswa.

\section{DAFTAR PUSTAKA}

\section{Buku}

Ahmad Syafii Maarif, 1995, Membumikan Islam, Yogyakarta: Pustaka Pelajar.

Ahmad Tafsir, 2006, Filsafat Pendidikan Islam, Bandung: Remaja Rosdakarya.

Departemen Agama Republik Indonesia. 2002. Al-Qur'an dan Terjemahnya, Jakarta: Departemen Agama.

H.A.R Tilaar. 2004, Perubahan Sosial Dan Pendidikan, pengantar pedagogik transformatif untuk indonesia, Jakarta: PT. Rineka Cipta.

M.. Nadjid Muchtar, 2005, Islam Ahlusunnah Waljama'ah Sejarah pemikiran dan dinamika NU di Indonesia, Jakarta.

Minto Rahayu, 2007, Pendidikan Kewarganegaraan (Perjuangan Menghidupi Jati Diri Bangsa), Jakarta: PT. Gramedia Widiasarana Indonesia.

Mochtar Zaman, 2012, Konstruksi Pendidikan Islam, Jakarta: Kalam-Media. Muhammad Tholchah Hasan, 2016, Pendidikan Multikulturalisme sebagai Opsi Penanggulangan Radikalisme, Malang: Universitas Islam Malang.

Musthafa Kamal Pasha, 2003, Pendidikan Kewarganegaraan (Civic Education), Jakarta: Citra Karsa Mandiri.

\section{Internet}

Endang Komara, Peran Pendidikan Islam dalam Era Globalisasi, http://www.geocities.ws/endang.komara/peran_pendidikan_islam_da lam_era_globalisasi.htm,akses 2 September 2017. 
MODEL PEMBELAJARAN PENDIDIKAN AGAMA ISLAM

DALAM MEMBENTUK SIKAP MULTIKULTURALISME (M. Jamhuri) 